\title{
BMJ Open Readiness of healthcare providers for e- hospitals: a cross-sectional analysis in China before the COVID-19 period
}

\author{
Peiyi Li, ${ }^{1,2,3}$ Yunmei Luo (D) , ${ }^{4}$ Xuexin Yu (D) , ${ }^{5}$ Elizabeth Mason, ${ }^{6}$ Zhi Zeng, ${ }^{7}$ \\ Jin Wen, ${ }^{7}$ Weimin Li (D) , ${ }^{8,9,10}$ Mohammad S Jalali (1) ${ }^{6,11}$
}

To cite: Li P, Luo Y, Yu X, et al. Readiness of healthcare providers for $\mathrm{e}$ hospitals: a cross-sectional analysis in China before the COVID-19 period. BMJ Open 2022;12:e054169. doi:10.1136/ bmjopen-2021-054169

- Prepublication history and additional supplemental material for this paper are available online. To view these files, please visit the journal online (http://dx.doi.org/10.1136/ bmjopen-2021-054169).

$\mathrm{PL}$ and $\mathrm{YL}$ contributed equally.

PL and YL are joint first authors.

Received 04 June 2021

Accepted 01 February 2022

Check for updates

(C) Author(s) (or their employer(s)) 2022. Re-use permitted under CC BY-NC. No commercial re-use. See rights and permissions. Published by BMJ.

For numbered affiliations see end of article.

Correspondence to

Dr Weimin Li;

weimi003@scu.edu.cn

\section{ABSTRACT}

Objectives The growth and development of smartphones and eHealth technologies have enabled the potential for extended care hospitals (e-hospitals) in China in order to facilitate the success of a primary healthcare centre (PHC)based integrated delivery model. Although the adoption of e-hospitals is essential, few studies have directed their research towards understanding the perspectives of healthcare providers. This study aims to identify the current readiness of healthcare providers to adopt ehospital technologies, determine the factors influencing this adoption and describe the perceived facilitators and barriers in regard to working at e-hospitals.

Design A cross-sectional study conducted in Sichuan, China, between June and September 2019.

Settings Information was collected from healthcare providers who have more than 3 years of work experience from a tertiary hospital, secondary hospital, PHCs and private hospital.

Participants 2298 medical professionals were included in this study.

Outcome measure This study included a selfadministered questionnaire that was used to assess participants' sociodemographic characteristics, online medical practices, willingness to use e-hospitals and perceived facilitators/barriers to working at e-hospitals. Multivariate regression analysis was performed in order to evaluate the independent factors associated with ehospital work.

Results Overall, $86.3 \%$ had a positive response towards working at e-hospitals. Age $(p<0.05)$, familiarity with e-hospitals $(p<0.001)$ and prior work practices in online healthcare settings $(p<0.001)$ were associated with participants' readiness to work at e-hospitals. Gender, education level, professional level, the tier of their affiliated hospital and workload were not statistically associated. Healthcare providers who had positive attitudes towards ehospitals considered improved efficiency, patient satisfaction, communication among physicians, increased reputation and income, and alleviated workload to be advantages of adoption. The participants who were unwilling to work at e-hospitals perceived lack of time, insufficient authenticity/ reliability and underdeveloped policies as potential barriers. Conclusion Improving operative proficiency in electronic devices, accommodating to work schedules, increasing familiarity with e-hospitals and regulating practices will improve the readiness of healthcare providers to work at e-hospitals.

\section{Strengths and limitations of this study}

- The current study investigated the healthcare providers' readiness towards e-hospitals and aim to provide a holistic and more complete view for Chinese policymakers/e-hospital developers.

- This study is the first to investigate the factors impacting the adoption of e-hospitals at this scale with respondents from various hospital levels. It provides useful implications for recognising healthcare providers' perceived facilitators and barriers to the use of e-hospitals and can lay the groundwork for the future conceptualisations of digital health in China.

- Even though this study covered various hospital levels in the Sichuan province, the results may not be generalised to other regions with different healthcare providers and characteristics.

- Also, since this is a cross-sectional study conducted before COVID-19, changes over time in attitudes towards e-hospitals due to rapid social development and population ageing were not captured.

\section{INTRODUCTION}

Since 2014, the Chinese government has suggested that the most cost-effective approach for healthcare delivery should focus on primary healthcare, with coordination between secondary and tertiary health institutions.$^{1}$ In principle, individuals should start treatment at primary healthcare centres (PHCs), which focus on populationbased prevention, case detection and disease management. Individuals should only proceed to secondary hospitals if the PHC is unable to cure and/or resolve the health issues. ${ }^{2}$ It has been proposed that tertiary hospitals should focus primarily on solving complicated diseases, and exclusively treat patients unable to be cured by other institutions. ${ }^{3}$ The primary care integrated delivery model would allow people to receive convenient care from nearby health providers. It would also help the Chinese healthcare system to meet emerging health needs and rising patient expectations that are caused by 
the rapidly ageing population and the increase in incidence of non-communicable diseases.

However, the inequitable distribution of healthcare providers has proven to be a major barrier to the adoption of this delivery approach. ${ }^{4}$ The vast majority of highly educated physicians and nurses are drawn to work at tertiary public hospitals due to their high salaries and prestigious reputations, while other medical professionals with fewer qualifications tend to fill positions at secondary hospitals and PHCs. ${ }^{5}$ Compounded with healthcare providers' unwillingness to relocate to PHCs and secondary hospitals, these tendencies have led to dominant patient preference for tertiary hospitals. ${ }^{6}$

As a priority eHealth project, e-hospitals were proposed by the National Health Commission of China as an innovative approach that harnessed online technologies to facilitate the exchange of health information for healthcare service delivery in 2015. E-hospitals, also known as extended care hospitals, are defined as an internet hospital which take the form of a smartphone app or website, and deliver outpatient service through an instant chatting platform. ${ }^{78}$ Two-way information can be delivered simultaneously in real time by videoconference, image or through a messaging platform. Thus, patients can stay at home or go to a medical institution near their home and meet through the e-hospital with a doctor who is based in a top-tier hospital. E-hospitals have the potential to improve access to high-quality health services as well as effectively reduce professional isolation and improve providers' performance in resourceconstrained environments. By providing opportunities for online health education, medical services, follow-ups and disease management, e-hospitals allow the delivery of high-quality services regardless of geographic, temporal, social, cultural and/or political barriers. ${ }^{910}$ In some ways, e-hospitals can serve as an alternative to traditional physical hospitals. On the other hand, e-hospitals can supplement traditional hospitals and integrate into the ongoing healthcare reform so that universal healthcare coverage can become more achievable. ${ }^{11}$

The predicted benefits of e-hospitals carry great promise for the implementation of a primary carecentred healthcare system in China. This technology empowers healthcare administrators to find solutions to issues related to the shortage of qualified doctors, especially in rural regions. It improves access to healthcare professionals, reducing referrals and minimising travel costs for patients. ${ }^{12}$ E-hospitals also provide essential assistance in the management of communicable diseases. For example, during crises such as the COVID-19 pandemic where demand for healthcare services grossly exceeds the capacity of hospital systems, e-hospitals could lessen the burden on physicians/hospitals as well as maximise the number of individuals given care and overall improve health outcomes. ${ }^{13}$ This could allow physicians to virtually instruct assessment and care for patients with milder cases who would have otherwise further crowded hospitals or suffered at home due to inadequate information about self-care. Furthermore, e-hospitals would allow patients with pre-existing non-related conditions to continue their care and/or rehabilitation from home with physician assistance while decreasing person-toperson contact. Visiting a physical hospital would further strain the resources/capacity and risk contracting infection from persons receiving treatment. E-hospitals would benefit those directly receiving online services and greatly improve the quality of care for patients in hospitals with critical conditions. These patients would be afforded more resources and physician attention due to the lesser crowding of facilities. ${ }^{14}$

China has 989 million internet users, with an internet penetration rate of $64.5 \%$, according to the China Internet Network Information Center. ${ }^{15}$ Ping An Good Doctor, one of the representative internet hospitals, had 300 million registered patient users as of October 2019, equivalent to one in every three Chinese netizens having using it, and the number of visitors exceeded 1.11 billion from April 2020 during the COVID-19 pandemic. ${ }^{16}$ Despite China's political commitment, significant financial investment in the technology and patients' demand, e-hospitals have not yet been fully adopted into the Chinese healthcare system. This is partly because the success of this healthcare innovation is dependent on the full adoption of e-hospitals by patients and acceptance by healthcare providers. ${ }^{17-19}$ The eHealth readiness, which has been positively associated with acceptance, is defined as the degree to which both healthcare providers and patients are prepared to engage with eHealth projects. ${ }^{20}$ While previous studies have assessed patient attitudes towards e-hospitals and theorised appropriate policy responses, few provide information about the concerns of healthcare providers. Studies have confirmed that eHealth readiness among doctors, nurses and allied healthcare professionals varies depending on their degree of exposure to online healthcare delivery methods. ${ }^{21}$ Unlike the private sector-dominated healthcare system in the USA, private hospitals in China are only intended to be supplements to public hospitals. ${ }^{22}{ }^{23}$ Therefore, public hospitals are able to hire more highly skilled physicians and provide quality services. In 2001, China's central government began to encourage the proliferation of private hospitals in an attempt to decentralise the role of tertiary public hospitals, which became increasingly possible as eHealth innovations continued to emerge. ${ }^{24}$ As a result, private hospitals now exist in addition to the three-tiered e-hospital system (PHCs, secondary and tertiary public hospitals). Thus, the readiness of healthcare providers from different medical institutions must be considered in the design of e-hospitals, and the factors that facilitate or hinder their adoption should be closely analysed.

The main objective of this study is to assess the factors influencing the providers' preparation to successfully take on e-hospitals. It also describes the factors that contribute to their acceptance or rejection of the technology in order to inform the integration of e-hospitals into the primary healthcare-centred delivery model. 


\section{METHODS}

\section{Study design}

Considering that cross-hospital care is one of the key benefits of e-hospitals, it was essential that providers from both private and public hospitals of all tiers were surveyed. Further, the Sichuan province located in West China, with a population of roughly 83.4 million people, was chosen for this investigation because it has more PHCs than any other province in China. ${ }^{25}$ Accordingly, we surveyed the following four medical institutions: West China Hospital of Sichuan University (tertiary hospital), First People's Hospital of Longquan District (secondary hospital), Community Health Centers of Chenghua District (PHCs) and Aidi Hospital (private hospital). This cross-sectional, questionnaire-based study was conducted between June and September 2019. Multistage convenience cluster sampling was conducted to make the sample representative.

\section{Questionnaire}

For the initial development of the questionnaire, we performed focus group interviews with 30 stakeholders, including healthcare providers, hospital administrators, information technicians and staff from the health insurance bureau, ministry of health and technical corporations. Based on the results and literature review, the preliminary questionnaire touched on a number of factors impacting the use of eHealth applications by providers as identified in the previous literature. Subsequently, the draft of the questionnaire was evaluated by a panel of five experts that included a medical doctor, statistician, nurse, healthcare policy researcher and e-hospital administrator to validate its contents with the intended constructs and theories. Content validity of the questionnaire was conducted with the item-level content validity index (CVI) which measured on a 4-point Likert scale, including different parameters such as relevance, clarity, simplicity and ambiguity. ${ }^{26}$ An item with CVI $>0.8$ was retained, and context-specific adjustments were made according to the feedback acquired from the expert panel. A pilot survey was then performed with 25 healthcare providers to evaluate the questionnaire, which mainly improved the interpretability of the questionnaire. Finally, a revised version of the questionnaire was produced for use in this research-see online supplemental multimedia appendix.

The questionnaire consisted of four sections, designed based on the transactional model of eHealth literacy, ${ }^{27}$ and 14 closed-ended questions that aimed to collect the user-oriented factor information from participants. The first section included questions relating to personal determinants of e-hospital readiness, such as participants' sociodemographic characteristics, which included gender, age, education level, department, years of practice, professional level, hospital type and length of time working. The second part of the questionnaire measured the technological user-oriented factor by measuring the respondents' experience and satisfaction with previous online medical services, based on a 5-point Likert scale. Part 3 assessed the familiarity with e-hospitals using a 5-point Likert scale and assessed the willingness to work at e-hospitals using binary answer choices, corresponding to the pre-existing knowledge. In the final section, respondents who reported willingness to use e-hospitals were asked their 'perceived facilitators', while the others were asked their 'perceived barriers', aiming to measure the rational support.

As for the validity and reliability of the questionnaire, we supplement the analyses that rely on the results of the survey as follows: Cronbach's $\alpha$ coefficient was employed to access the reliability of the test, and exploratory factor analysis was used to assess the structural validity. ${ }^{28} 29$ The overall Cronbach's $\alpha$ value for our scale was 0.76 . The Kaiser-Meyer-Olkin measure of sampling adequacy was 0.76 and the significance of Bartlett's test of sphericity was less than 0.001 . By factor analysis, the cumulative contribution rate of the five factors with characteristic root greater than 1 was 48.3. These results provide good reliability and validity of the survey.

\section{Participant selection, consent and data collection}

The questionnaire was published and shared through the hospitals' WeChat contacts using the web-based survey tool Sojump (Changsha Ran Xing InfoTech, China). Directors of the participating institutions were notified about the study via a memorandum drafted and signed by PYL. Once approval was obtained, the link to the survey was shared through the corresponding hospitals' WeChat contacts network which only gathered hospital directors and healthcare providers. Given all physicians in the WeChat contacts network were formal employees and thus had at least 3 years of residency training, all were eligible to participate in this study. Prior to participation, the purpose of the survey was introduced, the concept of e-hospitals was explained via a short text and the consent of participants was obtained through the WeChat network. Questionnaires were individually completed by the healthcare providers only once, since Sojump automatically checked that each participant's IP address only submitted one survey response. All centres received one reminder a week after the questionnaires were distributed. No compensation was provided to participation in the study.

\section{Data analysis}

Descriptive statistics were calculated for all survey items. Percentages and frequencies were evaluated for categorical variables, and mean values with SDs were calculated for continuous variables. For univariate analyses, a $\chi^{2}$ test was used for categorical variables, a t-test was used for continuous variables and a Kruskal-Wallis test was conducted to analyse the ordinal variables. Multiple significance tests were also used to examine whether there were existing differences among hospital tiers. However, years of experience were excluded from these analyses due to its multicollinearity with age. 
A $\chi^{2}$ test was performed to examine the association between willingness to use e-hospitals and other variables. Variables in the descriptive analysis were included in the multivariate regression model. Degree of knowledge about e-hospitals was enrolled as a continuous variable because it resulted in findings that did not significantly differ from those found when categorising the variable as ordinal $\left(\chi^{2}=4.1, p>0.05\right)$. Additionally, a $\chi^{2}$ test was employed to analyse hospital-related variations in perceived facilitators and barriers. SPSS (IBM SPSS, V.25, IBM) was used to perform the analysis. Two-tailed $p$ values $<0.05$ were considered statistically significant.

\section{Patient and public involvement}

No patient or public involvement took place in the design or conduct of this study. We involved healthcare providers, hospital administrators, experts in e-hospital systems, the ministry of health, public health researchers from various global settings in the design of this study and the survey tool. We intend to disseminate the main results to several stakeholders and health professionals globally by social media and personal contacts, including the participants of the study.

\section{RESULTS}

Baseline characteristics of study participants

Table 1 presents the baseline characteristics across the four hospitals. Overall, this study included 2298 participants with 379 being from the primary care centre, 552 from the secondary public hospital, 834 from the tertiary public hospital and 533 from the private hospital.

Several differences in the surveyed characteristics existed across the four hospitals. Participants in the secondary public hospital appeared to be older than those in the other three hospitals. Specifically, $20.8 \%$ of

Table 1 Sociodemographic data of the healthcare providers included in the study

\begin{tabular}{|c|c|c|c|c|c|c|}
\hline \multirow[b]{2}{*}{ Characteristics } & \multirow[b]{2}{*}{ Total } & \multicolumn{4}{|l|}{ Level of hospital } & \multirow[b]{2}{*}{$P$ value } \\
\hline & & $\begin{array}{l}\text { Primary healthcare } \\
\text { centre }\end{array}$ & $\begin{array}{l}\text { Secondary public } \\
\text { hospital }\end{array}$ & $\begin{array}{l}\text { Tertiary public } \\
\text { hospital }\end{array}$ & $\begin{array}{l}\text { Private } \\
\text { hospital }\end{array}$ & \\
\hline Age, $\mathrm{n}(\%)$ & & & & & & $<0.001 \dagger$ \\
\hline $18-29$ & $852(37.1)$ & $114(30.1)$ & $182(33.0)$ & $292(35.1)$ & $264(49.5)$ & \\
\hline 30-39 & $1053(45.8)$ & $202(53.3)$ & $255(46.2)$ & $413(49.5)$ & $183(34.4)$ & \\
\hline$\geq 50$ & $129(5.6)$ & $22(5.8)$ & $36(6.5)$ & $42(5.0)$ & $29(5.4)$ & \\
\hline Gender, n (\%) & & & & & & $<.001^{*}$ \\
\hline Male & $355(15.4)$ & $35(9.2)$ & $118(21.4)$ & $109(13.1)$ & $93(17.4)$ & \\
\hline Female & $1943(84.6)$ & $344(90.8)$ & $434(78.6)$ & 725 (86.9) & $440(82.6)$ & \\
\hline Master's degree or above & $153(6.7)$ & $4(1.1)$ & $60(10.9)$ & $64(7.7)$ & $25(4.7)$ & \\
\hline Professional title, n (\%) & & & & & & $<0.001 \dagger$ \\
\hline Junior & $1366(59.5)$ & $275(72.6)$ & $296(53.6)$ & $478(57.3)$ & $317(59.5)$ & \\
\hline Intermediate & $711(30.9)$ & $91(24.0)$ & $185(33.5)$ & $273(32.7)$ & $162(30.4)$ & \\
\hline Senior & $221(9.6)$ & $13(3.4)$ & $71(12.9)$ & $83(10.0)$ & $54(10.1)$ & \\
\hline Specialty, n (\%) & & & & & & $<.001^{*}$ \\
\hline Nurse & $1409(61.3)$ & 145 (38.3) & $292(52.9)$ & 703 (84.3) & $269(50.5)$ & \\
\hline Doctor & $889(38.7)$ & $234(61.7)$ & $260(47.1)$ & $131(15.7)$ & $264(49.5)$ & \\
\hline Years in practice, $\mathrm{n}(\%)$ & & & & & & $<0.001 \dagger$ \\
\hline
\end{tabular}

${ }^{*} \mathrm{X}^{2}$ test.

†Kruskal-Wallis test. 
participants in the secondary public hospital were over the age of 40 . This was only true for $16.1 \%$ of participants in the private hospital, $15.4 \%$ in the tertiary hospital and $16.6 \%$ in the primary care centre $(\mathrm{p}<0.001)$. While the vast majority of our participants had bachelor-level education or above $(96.2 \%)$, the primary care centre $(8.4 \%)$ and private hospital $(5.8 \%)$ had higher proportions of providers who did not have a bachelor's degree $(p<0.001)$. The hierarchy in these organisations includes juniors, intermediates and seniors; higher titles have more experience, skill and academic achievement and certifications. ${ }^{30}{ }^{31}$ The primary care centre had a lowest percentage of senior providers $(3.4 \%)$ compared with others $(\mathrm{p}<0.001)$.

Interestingly, we found that the percentage of nurses in the tertiary public hospital $(84.3 \%)$ was significantly higher than that of the other three hospitals $(p<0.001)$. We also found that $64.7 \%$ of participants at the private hospital had been practising for less than 10 years, which was significantly higher than those $(\mathrm{p}<0.001)$. Lastly, $47.1 \%$ of our participants worked over 40 hours/week, with this being highest for the private hospital (73.4\%), and lower for the primary care centre $(19.5 \%)$, tertiary hospital (32.0\%) and secondary public hospital (63.3\%) $(\mathrm{p}<0.001)$.

Variations in knowledge, usage and satisfaction of e-hospitals Table 2 presents the results regarding participants' familiarity with e-hospital, usage and satisfaction with previous online medical service technologies. Participants in the tertiary public hospitals appeared to have a better familiarity of e-hospitals, given that the highest proportion of participants reported being very familiar with e-hospitals $(13.7 \%, \mathrm{p}<0.001)$. Overall, $59.6 \%$ of healthcare providers stated that they have a work history of online medical practices, while it is more commonplace for healthcare providers in tertiary hospitals $(\mathrm{p}<0.001)$. Moreover, $75.0 \%$ of current users reported that they were satisfied with their previous online medical practices.

\section{Variations in willingness to work at e-hospitals}

Table 3 shows the results from the descriptive analyses. Among the 2298 participants, 314 individuals (13.7\%) reported that they were not willing to work at an e-hospital. Younger participants were found to be more willing to work at e-hospitals relative to older participants

Table 2 Present usage and satisfaction of online medical practices among healthcare providers

\begin{tabular}{|c|c|c|c|c|c|c|}
\hline \multirow[b]{2}{*}{ Characteristics } & \multirow[b]{2}{*}{ Total } & \multicolumn{4}{|c|}{ Level of working hospital } & \multirow[b]{2}{*}{$P$ value } \\
\hline & & $\begin{array}{l}\text { Primary healthcare } \\
\text { centre }\end{array}$ & $\begin{array}{l}\text { Secondary public } \\
\text { hospital }\end{array}$ & $\begin{array}{l}\text { Tertiary public } \\
\text { hospital }\end{array}$ & $\begin{array}{l}\text { Private } \\
\text { hospital }\end{array}$ & \\
\hline Sample size, $n$ & 2298 & 379 & 552 & 834 & 533 & \\
\hline \multicolumn{2}{|l|}{$\begin{array}{l}\text { Degree of familiarity towards e- } \\
\text { hospitals, } n(\%)\end{array}$} & & & & & $<0.001 \dagger$ \\
\hline Very familiar with & $212(9.2)$ & $25(6.6)$ & $54(9.8)$ & $114(13.7)$ & $19(3.6)$ & \\
\hline Know a good bit & $962(41.9)$ & $149(39.3)$ & $248(44.9)$ & $349(41.8)$ & $216(40.5)$ & \\
\hline Only heard of & $568(24.7)$ & $115(30.3)$ & $129(23.4)$ & $123(14.7)$ & $201(37.7)$ & \\
\hline Never heard of & $57(2.5)$ & $14(3.7)$ & $5(0.9)$ & $6(0.8)$ & $32(6.0)$ & \\
\hline Sample size-online medical users & 1369 & 195 & 338 & 617 & 219 & $<0.001^{*}$ \\
\hline \multicolumn{7}{|c|}{ Category of the online medical practices, $\mathrm{n}(\%) \neq$} \\
\hline Interpreting test reports & $530(38.7)$ & $30(15.4)$ & $156(46.2)$ & $273(44.2)$ & $71(32.4)$ & $<.001^{*}$ \\
\hline $\begin{array}{l}\text { Online follow-up and rehabilitation } \\
\text { guidance }\end{array}$ & $558(40.8)$ & $43(22.1)$ & $131(38.8)$ & $296(48.0)$ & $88(40.2)$ & $<.001^{*}$ \\
\hline Managing chronic diseases & $541(39.5)$ & $129(66.2)$ & $114(33.7)$ & $249(40.4)$ & $49(22.4)$ & $<.001^{*}$ \\
\hline \multicolumn{6}{|c|}{ Degree of satisfaction of the online medical practices, $\mathrm{n}(\%)$} & $<0.001 \dagger$ \\
\hline Extremely satisfied & $399(29.2)$ & $44(22.6)$ & $80(23.7)$ & $228(37.0)$ & $47(21.4)$ & \\
\hline Satisfied & $627(45.8)$ & $85(43.6)$ & $173(51.2)$ & $277(44.8)$ & $92(42.1)$ & \\
\hline Neutral & $321(23.4)$ & $60(30.8)$ & $78(23.1)$ & $104(16.9)$ & 79 (36.1) & \\
\hline Dissatisfied & $16(1.2)$ & $5(2.5)$ & $5(1.5)$ & $5(0.8)$ & $1(0.4)$ & \\
\hline
\end{tabular}

${ }^{*} \mathrm{X}^{2}$ test.

†Kruskal-Wallis test.

$\ddagger$ There are overlaps among the responses to these categories. 
Table 3 Willingness to work at e-hospitals

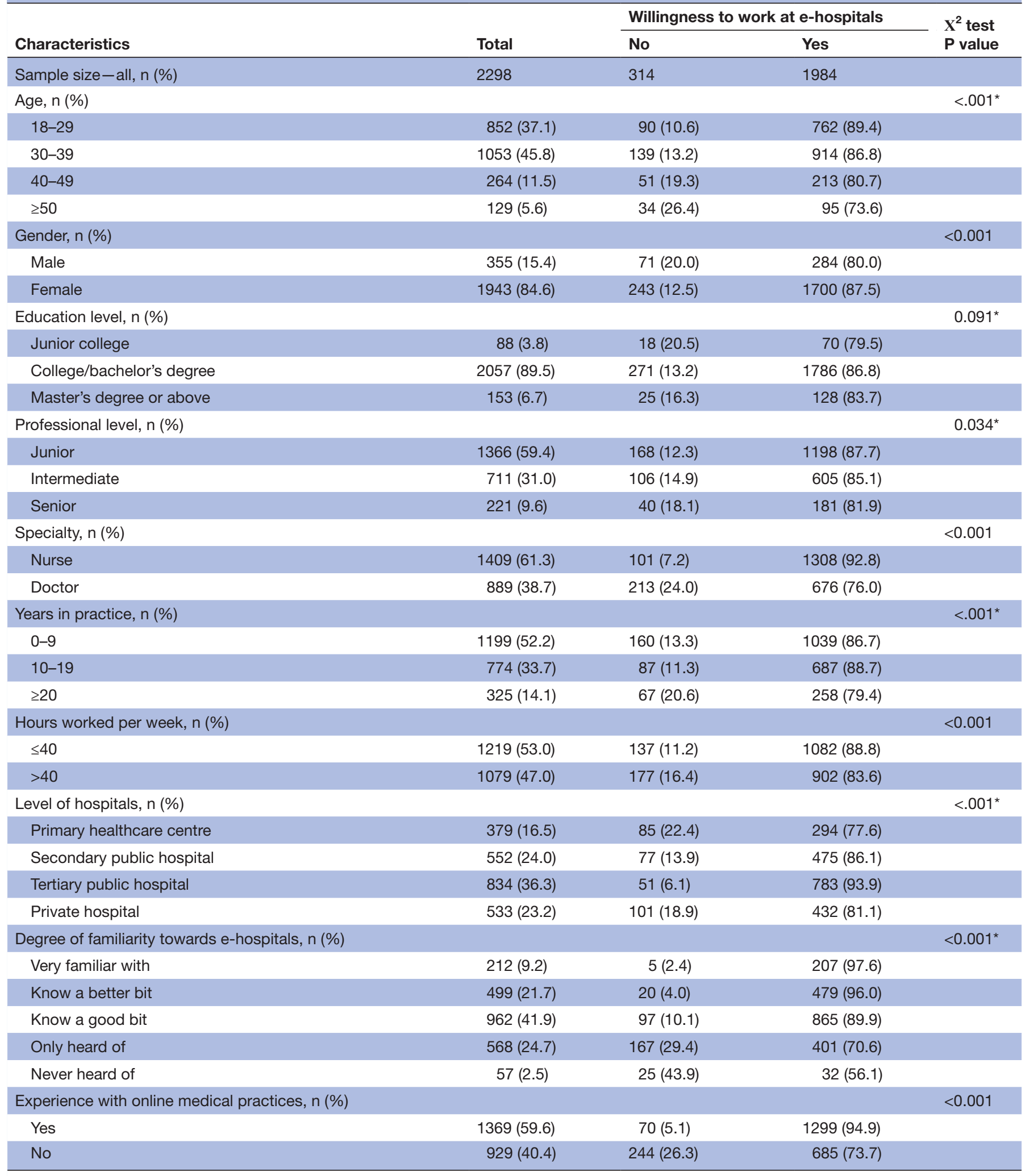

*Kruskal-Wallis test.

$(\mathrm{p}<0.001)$. Female participants $(87.5 \%)$ were more willing to work at an e-hospital when compared with male participants $(80.0 \%) \quad(\mathrm{p}<0.001)$. Junior participants $(87.7 \%)$ were most willing to work at an e-hospital, followed by intermediate $(85.1 \%)$, and then senior participants $(81.9 \%)(\mathrm{p}<0.001)$.

Compared with physicians $(76.0 \%)$, nurses $(92.8 \%)$ were more willing to work at an e-hospital $(\mathrm{p}<0.001)$. 
Table 4 Multivariate logistic regression of the willingness to work at e-hospitals

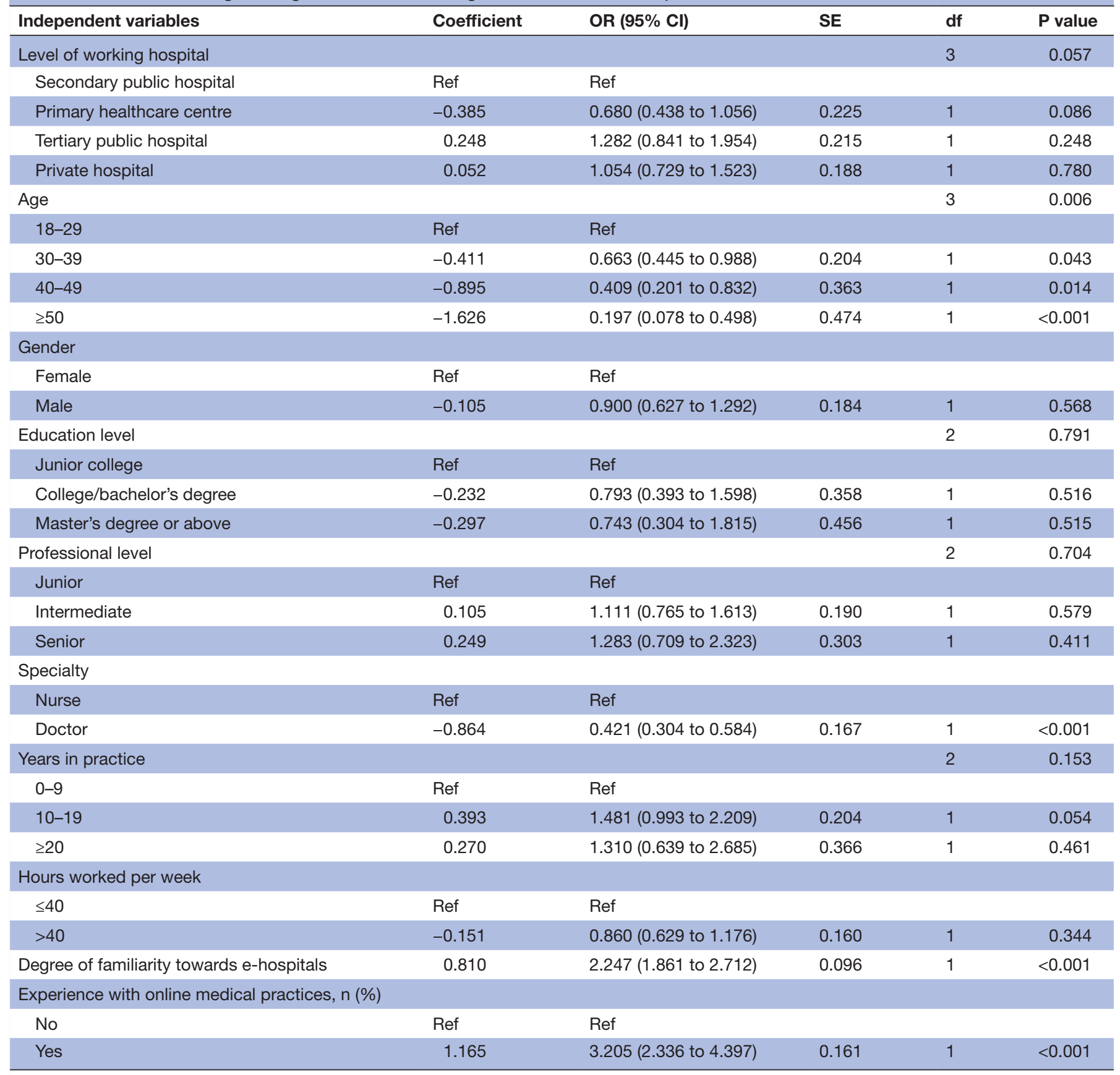

$-2 \ln L=1425.986$; Hosmer and Lemeshow test: $\chi^{2}=5.043, p=0.753$.

Participants with 10-19 years of experience (88.7\%) appeared to be most willing to work at an e-hospital $(\mathrm{p}<0.001)$. Unsurprisingly, the proportion of providers currently working over 40 hours/week who were willing to work at an e-hospital $(83.6 \%)$ was lower than those who worked less than 40 hours/week $(88.7 \%)(p<0.001)$. Moreover, participants who were more familiar with e-hospitals were more likely to report that they were willing to work for one $(p<0.001)$. Results also indicated that individuals with previous online medical practices were more willing to conduct their work in e-hospital platforms $(\mathrm{p}<0.001)$.
Table 4 presents the results of multivariate analysis, showing that the level of affiliated hospitals, education, professional level and working hours/week were not statistically associated with the willingness to work at e-hospitals after adjusting for other covariates in the model. Results further suggested that compared with those $18-29$ years of age, individuals aged $30-39.9(\mathrm{OR}=0.663$, $\mathrm{p}=0.043)$ and $40-49.9(\mathrm{OR}=0.409, \mathrm{p}=0.014)$, and over 50 $(\mathrm{OR}=0.197, \mathrm{p}<0.001)$ were less willing to work at e-hospitals. Nurses were found to be more willing to work at e-hospitals relative to physicians (nurses vs physicians, $\mathrm{OR}=0.421, \mathrm{p}<0.001)$. Also, participants with a better 
familiarity with e-hospitals were more willing to work at e-hospitals $(\mathrm{OR}=2.247, \mathrm{p}<0.001)$. In addition, clinicians with online working practices had a higher likelihood of being willing to work at e-hospitals compared with those without an online working background $(\mathrm{OR}=3.205$, $\mathrm{p}<0.001)$.

\section{Variations in perceived facilitators and barriers}

Among the 1984 participants who were willing to work at e-hospitals, over $90 \%$ perceived that it could improve the convenience and efficiency of healthcare. Participants from tertiary public hospitals $(94.6 \%)$ appeared to be more concerned with improving convenience and efficiency relative to those from other hospitals $(p<0.001)$. A statistically higher proportion of participants from the tertiary public hospital considered e-hospitals to be a potential tool for alleviating workload $(66.8 \%, \mathrm{p}<0.001)$ and improving patient satisfaction $(72.8 \%, \mathrm{p}<0.001)$. Similarly, a significantly higher proportion of participants from private hospitals perceived it as a way for physicians to communicate with and learn from one another $(41.9 \%, \mathrm{p}<0.001) .19 .6 \%$ of participants in the secondary public hospital considered working at an e-hospital to be a way to increase their income and reputation $(p<0.001)$.

Several barriers were identified from the 314 participants who were unwilling to work at e-hospitals. Among them, $18.5 \%$ reported that they were not willing to work at an e-hospital because they were unable to operate smart devices (this figure did not differ across the four hospitals). In addition, $48.4 \%$ reported that they did not have extra time to work at an e-hospital. The proportion of participants from secondary hospitals that reported this $(67.5 \%)$ was statistically higher than those from tertiary public hospitals $(51.0 \%)$, primary care centres $(36.5 \%)$ and private hospitals $(42.6 \%)(\mathrm{p}<0.001)$. Furthermore, $43.6 \%$ of participants were not willing to work at an e-hospital because they believed that the current licences for multisited and medical disputes for e-hospitals are not fully developed. $53.5 \%$ of participants reported that they believed e-hospitals were not reliable and $18.2 \%$ said that they were concerned that e-hospitals had not been well received by the patients. No variations in the last three barriers existed among participants across the four hospitals. Figures 1 and 2 present the perceived facilitators

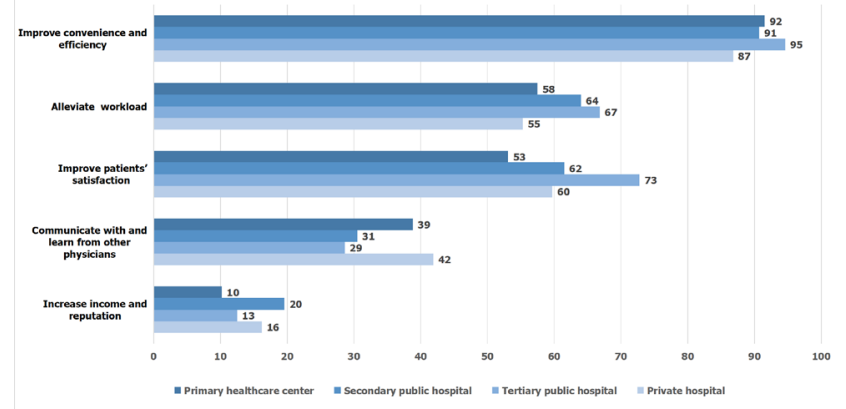

Figure 1 Perceived facilitators for e-hospital workers (\%).

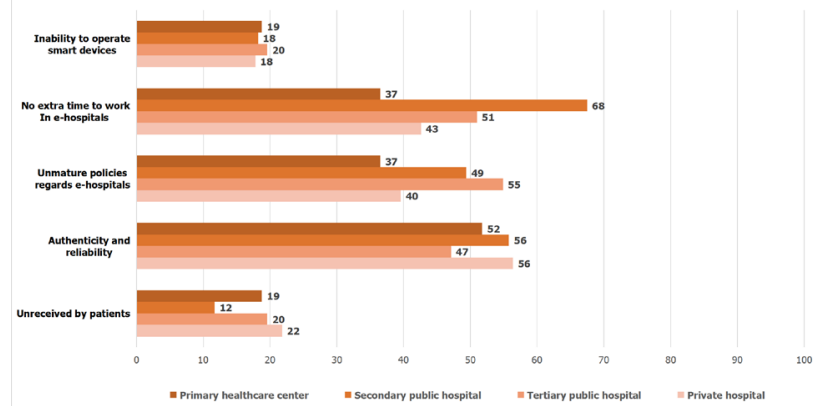

Figure 2 Perceived barriers for non-workers (\%).

for workers of e-hospitals and barriers for non-workers, respectively.

\section{DISCUSSION}

Many contend that eHealth technologies hold promises for enhanced efficiency and quality of healthcare. ${ }^{32}{ }^{33}$ No studies have been conducted to assess the attitudes of healthcare providers towards e-hospitals or their respective facilitators/barriers towards its adoption in China. This research attempts to address this informational gap and provide insight for decision makers in China, especially since eHealth has been proposed as a part of antiCOVID-19 strategy.

Research has shown that computer proficiency is positively associated with the acceptability of eHealth technologies. ${ }^{34}$ However, in this study, one of the key results found that it was the physicians' age, not their information technology (IT) skills, that affects their readiness for the adoption of e-hospitals. Specifically, younger participants usually presented higher willingness towards e-hospitals. One possibility is that the younger physicians are generally equipped with higher computer proficiency and more familiar with electronic health records (EHRs) as well as healthcare information systems (HIS), which enables them to be more open to e-hospitals. Alternatively, given the early healthcare system was less informationised, older generation physicians at that time are less likely to have received telehealth training during their residency. Although the healthcare system has gradually become more digitised in the last decades, nevertheless, those older generation physicians also become seniors over time, which were more likely to give verbal orders, treatment plan and prescriptions, not work directly with EHRs or the HIS, making them missing telehealth training, lacking technological proficiency. ${ }^{36}$ Given that patients often prefer treatment from senior physicians when visiting e-hospitals, it is essential that the readiness of senior providers is prioritised. Therefore, upguided operational skills training, including e-hospital curricula, is implemented and that postgraduate e-hospital accreditation is mandated. Additionally, designing a user-friendly app and providing 24-hour technical assistants may be 
also critical for facilitating the older physicians' engagement with e-hospitals in China. ${ }^{37}$

Considering that nurses are usually more focused on direct, physical patient care, while physicians are more involved in handling patients' diagnoses, and treatments and prescriptions, the priority of nurses in facilitating e-hospital initiatives was presumed to be lower in comparison to physicians. Although physicians are deemed the most important for the adoption and implementation of eHealth services ${ }^{38}$ we found that nurses were significantly more willing to work in e-hospitals than the physicians. The positive association between nurses and willingness to work at e-hospitals may be attributed to the ability of e-hospital visits to provide flexibility in healthcare location, thus the patient would transfer from offline to online, which might have been especially helpful for significantly decreased physical labour for nurses attributing to decrease the number of offline visiting patients. However, in this context, the workload for physicians may increase since e-hospitals will allow for additional counselling patients, who previously had not been able to reach the hospital, to receive care. Thus, in order to access the potential advantages of e-hospitals, it may be necessary for policymakers to prioritise the workload concerns of physicians. ${ }^{39}$ For example, to address these concerns, government and hospital administrators could designate specific times during the workday for virtual consultations. Additionally or alternatively, administrators could also provide performance incentives for professionals who elect to work at e-hospitals. ${ }^{40}$

Our participants who had previous experience with online medical practices reported being more willing to work at e-hospitals, which is consistent with prior research. ${ }^{41}$ Thus, clinicians in locations where healthcare is less integrated with technology may be especially unlikely to realise or recognise the advantages of e-hospitals. However, our study was conducted in Western China, where the economy is relatively underdeveloped compared with Beijing and Shanghai, and only half of the participants had experience with online medical practices in this region. The lesser prevalence of IT trend in healthcare in Western China may be explained by the limited financial support for establishment, management and maintenance of current HIS. ${ }^{42}$ Thus, it is important that local decision makers give priority to allocating funding for the development of HIS in order to further the progress of e-hospitals. Furthermore, hardware infrastructures and internet access are necessary for e-hospitals to function; however, they may not be affordable for smaller institutions such as PHC. $^{43}{ }^{44}$ In our study, PHCs had less online medical practices, which may be explained by variation in the accessibility of infrastructure needed to provide online care. Therefore, policymakers should take corresponding strategic approaches to address this concern, such as increasing funding for PHCs.

In our results, it was found that familiarity with e-hospitals was one of the prerequisites for readiness to adopt e-hospitals. To increase knowledge and awareness among healthcare professionals, e-hospital training should be an integral part of advanced education for hospital employees. Furthermore, e-hospital curriculum for undergraduates' medical education should be established to increase the familiarity among next generation of medical providers.

In this study, improved efficiency, patient satisfaction, communication among physicians, increased provider reputation and income, and alleviated workload were perceived by participants as key facilitators for e-hospital work. Meanwhile, the top perceived barriers included: difficulty of use, lack of extra time, dubious authenticity and reliability, negative patient attitudes and underdeveloped policy. Specifically, our findings revealed that the most common perceived facilitator for e-hospitals among willing providers at tertiary hospitals was the alleviation of workload. However, workload was also the most frequently mentioned concern among unwilling providers. In light of this, e-hospital and physical hospital administrators should ensure that healthcare providers continue to have reasonable working hours while balancing offline and online workload. Furthermore, interviews with healthcare providers and IT designers are necessary to effectively identify and integrate clinical demands into user-friendly e-hospital platforms. Furthermore, outpatient fees of e-hospitals must be set to a price that is both affordable to patients and enticing for physicians.

Concerns regarding the authenticity/reliability must also be addressed so that e-hospitals can be successful staples of the primary care-centred integrated delivery model. Fear of inadequate data protection is a prominent concern regarding the adoption of healthcare IT among physicians. In addition to data security and privacy, the service quality conducted by e-hospitals also worried physicians. Though there are currently many e-hospital systems within the Chinese healthcare market, none fulfil the requirements for patient safety, nor are there any scientific entities responsible for evaluating e-hospitals' service quality. To address these shortcomings, e-hospitals should be implemented according to criteria that will guarantee quality and continuity of clinical care. Establishing an e-hospital management department and designing reliable treatment protocol and evaluation mechanisms for e-hospitals is imperative for decision makers and policymakers to ensure that the quality of healthcare is protected. ${ }^{41}{ }^{42}$ Finally, structural and organisation guidelines for e-hospitals must be developed and government real-time regulation of data security surrounding e-hospitals must be enacted in order to further encourage physicians' adoption. ${ }^{43-45}$ Moreover, developed policies are not well proposed yet. Evidence-based policy research regarding e-hospitals and Information and communications technology-guided healthcare reform should continue to be explored to aid policymaking.

For decades, the private sector in China has received minimal attention from policymakers. However, recent years have brought an interest in its potential. We believe that the integration of private hospitals into the e-hospital 
delivery cycle is necessary for the success of the primary care-centred integrated model and the promotion of communication between public and private hospitals. Through this increased connectivity of private and public hospitals, the best possible outcomes may be achieved and resources may be accessed for patients in China. ${ }^{46}$

\section{Strengths, limitations and future research}

This study has several limitations. First, its participant sample was only drawn from hospitals in the Sichuan province by convenience sampling, and thus the results may not be generalised to other regions with different healthcare providers and characteristics. The degree of IT development and economic conditions constrained the generalisability of our results. Second, although the present study contained various healthcare providers from different departments, we could not precisely estimate the differences among subgroups due to the limited sample size across specialists. Further studies are recommended to investigate these nuances. Moreover, due to the constraint of time of respondents, our survey lacked open-ended response options and qualitative interviews, which would have allowed for the collection of more specific information from respondents. Also, since this is a cross-sectional study which was conducted before the COVID-19 pandemic, changes in physicians' attitude and willingness towards e-hospitals caused by the pandemic are hard to evaluate as sudden increases in telehealth visits were observed during the pandemic. Finally, changes over time in attitudes towards e-hospitals due to rapid social development and population ageing were also not captured.

Nevertheless, this study is the first to investigate the factors impacting the adoption of e-hospitals at this scale with respondents from various hospital levels. It provides useful implications for recognising healthcare providers' perceived facilitators and barriers to the use of e-hospitals and can lay the groundwork for the future conceptualisations of digital health in China. The results of this study have been providing insights into physicians' participation towards e-hospitals, especially if the epidemic has weakened its boosting effect on e-hospital usage in the future.

The Chinese healthcare system must enhance its responsiveness and capacity to meet the imperative needs of the ageing population, especially given the burden of communicable and non-communicable diseases. Although e-hospitals have evidence-based value in the delivery of healthcare services, it is important to note that these advantages cannot be accessed without patient demand for e-hospitals and cooperation from healthcare providers. ${ }^{47}$ Despite efforts that have been made, the e-hospital technology is imperfect, and therefore further studies are needed to support policies and expand available resources for this critical infrastructure. ${ }^{48}$ In addition, cost-benefit analysis and outcome evaluations are encouraged ${ }^{49}$ Moreover, although the present study contained various healthcare providers from different departments, we could not estimate the differences among subgroups due to the limited sample size across specialists. Further studies are recommended to investigate these nuances on the specific attitudes and perceptions of specialists, such as psychiatrists, geriatricians and general practitioners. Issues of quality and accessibility must also be taken into consideration for future research.

\section{Author affiliations}

${ }^{1}$ Department of Anesthesiology, Sichuan University West China Hospital, Chengdu, Sichuan, China

${ }^{2}$ Laboratory of Anesthesia and Critical Care Medicine, National-Local Joint Engineering Research Centre of Translational Medicine of Anesthesiology,West China Hospital, Sichuan University, Chengdu, Sichuan, China

${ }^{3}$ The Research Units of West China (2018RU012)-Chinese Academy of Medical Sciences, West China Hospital, Sichuan University, Chengdu, Sichuan, China

${ }^{4}$ West China Medical Publishers, West China Hospital, Sichuan University, Chengdu, Sichuan, China

${ }^{5}$ Biomedical Big Data Center, Sichuan University West China Hospital, Chengdu,

Sichuan, China

${ }^{6}$ MGH Institute for Technology Assessment, Harvard Medical School, Boston, Massachusetts, USA

${ }^{7}$ Institute of Hospital Management, Sichuan University, West China Hospital, Chengdu, Sichuan, China

${ }^{8}$ Department of Respiratory and Critical Care Medicine, Sichuan University West China Hospital, Chengdu, China

${ }^{9}$ Institute of Respiratory Health, Frontiers Science Center for Disease-related Molecular Network, West China Hospital, Sichuan University, Chengdu, Sichuan, China

${ }^{10}$ Precision Medicine Research Center, West China Hospital, Sichuan University, Chengdu, Sichuan, China

${ }^{11}$ Massachusetts Institute of Technology Sloan School of Management, Cambridge, Massachusetts, USA

Acknowledgements We sincerely thank the four medical institutions and all participating physicians who shared their perspectives throughout this study. The authors would like to acknowledge Yan Jiang, Zi Liu, Li Ma, Qiqiang Xiao and Wenqi Zeng for their clinical assistance, and Guanhua Qing for his assistance and Yusui Zhao for his suggestions in this manuscript.

Contributors PL conducted the literature search, conceived the study design and questionnaire, carried out the survey and drafted the manuscript. YL led the design of the questionnaire, data collection, analysis and interpretation. XY was involved in the statistical analysis and interpretation of data. ZZ provided comments and suggestions in revisions of the paper. JW helped with the designing of the questionnaire and provided scientific input. EM and MSJ consulted the analysis, contributed to further development of the analysis and content and revised the manuscript for important intellectual content. WL was acting as the guarantor, and responsible for all the results of the study, as well as the review and approval of the manuscript. All authors read and approved the final manuscript. EM and XY contributed equally as co-second author.

Funding This work was supported by the 1.3.5 project for disciplines of excellence, West China Hospital, Sichuan University (ZYJC18001 to WML); CAMS Innovation Fund for Medical Science (No: 2019TX310002 to WML); and National Guided Science and Technology Development Project of Sichuan Province (No: 2020ZYD009 to WML).

Competing interests None declared.

Patient consent for publication Not applicable.

Ethics approval This study involves human participants and ethical approval to conduct the study was obtained from the Research Ethics Committee of the West China Hospital of Sichuan University (№ 2019(343)). Verbal consent was preferred and approved. All collected data are kept confidential. Participants gave informed consent to participate in the study before taking part.

Provenance and peer review Not commissioned; externally peer reviewed.

Data availability statement Data are available upon reasonable request. Data are available upon request. 
Supplemental material This content has been supplied by the author(s). It has not been vetted by BMJ Publishing Group Limited (BMJ) and may not have been peer-reviewed. Any opinions or recommendations discussed are solely those of the author(s) and are not endorsed by BMJ. BMJ disclaims all liability and responsibility arising from any reliance placed on the content. Where the content includes any translated material, BMJ does not warrant the accuracy and reliability of the translations (including but not limited to local regulations, clinical guidelines, terminology, drug names and drug dosages), and is not responsible for any error and/or omissions arising from translation and adaptation or otherwise.

Open access This is an open access article distributed in accordance with the Creative Commons Attribution Non Commercial (CC BY-NC 4.0) license, which permits others to distribute, remix, adapt, build upon this work non-commercially, and license their derivative works on different terms, provided the original work is properly cited, appropriate credit is given, any changes made indicated, and the use is non-commercial. See: http://creativecommons.org/licenses/by-nc/4.0/.

\section{ORCID iDs}

Yunmei Luo http://orcid.org/0000-0002-2661-3214

Xuexin Yu http://orcid.org/0000-0002-6484-6035

Weimin Li http://orcid.org/0000-0003-0985-0311

Mohammad S Jalali http://orcid.org/0000-0001-6769-2732

\section{REFERENCES}

1 Yip W, Hsiao W. Harnessing the privatisation of China's fragmented health-care delivery. Lancet 2014;384:805-18.

2 Wang X, Sun X, Birch S, et al. People-centred integrated care in urban China. Bull World Health Organ 2018;96:843-52.

3 Yip W, Fu H, Chen AT, et al. 10 years of health-care reform in China: progress and gaps in universal health coverage. Lancet 2019;394:1192-204.

$4 \mathrm{Li} \mathrm{X,} \mathrm{Lu} \mathrm{J,} \mathrm{Hu} \mathrm{S,} \mathrm{et} \mathrm{al.} \mathrm{The} \mathrm{primary} \mathrm{health-care} \mathrm{system} \mathrm{in} \mathrm{China.}$ Lancet 2017;390:2584-94.

5 Zhang L, Cheng G, Song S, et al. Efficiency performance of China's health care delivery system. Int $J$ Health Plann Manage 2017;32:254-63.

6 Dai J, Wang X, Ayala FJ. Medical Informatics and the "Three Long, One Short" Problem of Large Urban Hospitals in China. JAMA 2016;316:269-70.

7 Ekeland AG, Hansen AH, Bergmo TS. Clinical videoconferencing as eHealth: a Critical-Realist review and qualitative Meta-Synthesis. $J$ Med Internet Res 2018;20:e282.

8 Eysenbach G. What is e-health? J Med Internet Res 2001;3:E20.

9 Li P, Liu X, Mason E, et al. How telemedicine integrated into China's anti-COVID-19 strategies: case from a national referral center. BMJ Health Care Inform 2020;27:e100164

10 Tu J, Wang C, Wu S. The Internet Hospital: an emerging innovation in China. Lancet Glob Health 2015;3:e445-6.

11 Null R, Wei J. Value increasing business model for e-hospital. Int J Electron Healthc 2009;5:48-67.

12 Alonso SG, de la Torre Díez I, Zapiraín BG. Predictive, personalized, preventive and participatory (4P) medicine applied to telemedicine and eHealth in the literature. J Med Syst 2019;43:140.

13 Greenhalgh T, Wherton J, Shaw S, et al. Video consultations for covid-19. BMJ 2020;368:m998.

14 Hollander JE, Carr BG. Virtually perfect? telemedicine for Covid-19. N Engl J Med 2020;382:1679-81.

15 45th statistical report on internet development in China [in Chinese]. China Internet network information center. Available: http://www. cnnic.net.cn/hlwfzyj/hlwxzbg/hlwtjbg/202004/t20200428_70974.htm [Accessed 01 Jun 2020].

16 The registered users of Ping An internet hospital exceeded 300 million [in Chinese]. People.cn. Available: http://sh.people.com.cn/ n2/2019/0923/c134768-33379897.html [Accessed 01 Jun 2020].

17 Leigh S, Ashall-Payne L. The role of health-care providers in mHealth adoption. Lancet Digit Health 2019;1:e58-9.

18 Liyanage H, Correa A, Liaw S-T, et al. Does informatics enable or inhibit the delivery of patient-centred, coordinated, and quality-assured care: a Delphi study. A contribution of the IMIA primary health care informatics Working group. Yearb Med Inform 2015;10:22-9.

19 Warraich HJ, Califf RM, Krumholz HM. The digital transformation of medicine can revitalize the patient-clinician relationship. NPJ Digit Med 2018:1:49.

20 Khoja S, Scott R, Gilani S. E-health readiness assessment: promoting "hope" in the health-care institutions of Pakistan. World Hosp Health Serv 2008;44:36-8.
21 Biruk S, Yilma T, Andualem M, et al. Health professionals' readiness to implement electronic medical record system at three hospitals in Ethiopia: a cross sectional study. BMC Med Inform Decis Mak 2014; $14: 115$

22 Tang C, Zhang Y, Chen L, et al. The growth of private hospitals and their health workforce in China: a comparison with public hospitals. Health Policy Plan 2014;29:30-41.

23 Pan J, Zhao H, Wang X, et al. Assessing spatial access to public and private hospitals in Sichuan, China: the influence of the private sector on the healthcare geography in China. Soc Sci Med 2016;170:35-45.

24 General Office of the State Council. Notice on advices on supporting social forces in the provision of diversified medical services. Available: http://www.gov.cn/zhengce/content/2017-05/23/content_ 5196100.htm [Accessed 23 May 2017].

25 Statistical Bureau of Sichuan. NBS survey office in Sichuan: Sichuan statistical yearbook. Beijing: China Statistics Press, 2017.

26 Polit DF, Beck CT. The content validity index: are you sure you know what's being reported? critique and recommendations. Res Nurs Health 2006;29:489-97.

27 Paige SR, Stellefson M, Krieger JL, et al. Proposing a Transactional model of eHealth literacy: concept analysis. J Med Internet Res 2018;20:e10175.

28 Arsenault-Lapierre G, Sourial N, Pakzad S, et al. Validation of a questionnaire for family physicians: knowledge, attitude, practice on dementia care. Can J Aging 2021;40:238-47.

29 Zhao Y, Xu S, Wang L, et al. Concerns about information regarding COVID-19 on the Internet: cross-sectional study. J Med Internet Res 2001;22:E20487.

30 Wang Y, Liu L, Xu H. Alarm bells ring: suicide among Chinese physicians: a STROBE compliant study. Medicine 2017;96:e7790.

31 Yuan H-F, Xu W-D, Hu H-Y. Young Chinese doctors and the pressure of publication. Lancet 2013;381:e4.

32 Wicks P, Stamford J, Grootenhuis MA, et al. Innovations in e-health. Qual Life Res 2014;23:195-203.

33 Chaudhry B, Wang J, Wu S, et al. Systematic review: impact of health information technology on quality, efficiency, and costs of medical care. Ann Intern Med 2006;144:742-52.

34 Olok GT, Yagos WO, Ovuga E. Knowledge and attitudes of doctors towards e-health use in healthcare delivery in government and private hospitals in northern Uganda: a cross-sectional study. BMC Med Inform Decis Mak 2015;15:87.

35 Saigí-Rubió F, Torrent-Sellens J, Jiménez-Zarco A. Drivers of telemedicine use: comparative evidence from samples of Spanish, Colombian and Bolivian physicians. Implement Sci 2014;9:128.

36 Wang C, Chen S, Zhu J, et al. China's new $4+4$ medical education programme. Lancet 2019;394:1121-3.

37 Yagos WO, Tabo Olok G, Ovuga E. Use of information and communication technology and retention of health workers in rural post-war conflict Northern Uganda: findings from a qualitative study. BMC Med Inform Decis Mak 2017;17:6.

38 Duplaga M, Andrychiewicz A, Dańda J. The opinions about e-health among nurses employed in hospitals located in an urban area in Poland. Comput Inform Nurs 2013;31:281-9.

39 Deng Z, Hong Z, Zhang W, et al. The effect of online effort and Reputation of physicians on patients' choice: 3-Wave data analysis of China's good doctor website. J Med Internet Res 2019;21:e10170.

40 Shaw RJ, Kaufman MA, Bosworth HB, et al. Organizational factors associated with readiness to implement and translate a primary care based telemedicine behavioral program to improve blood pressure control: the HTN-IMPROVE study. Implement Sci 2013;8:106.

41 Ruiz Morilla MD, Sans M, Casasa A, et al. Implementing technology in healthcare: insights from physicians. BMC Med Inform Decis Mak 2017;17:92

42 Mauco KL, Scott RE, Mars M. Critical analysis of e-health readiness assessment frameworks: suitability for application in developing countries. J Telemed Telecare 2018;24:110-7.

43 Moore MA, Coffman M, Jetty A, et al. Family physicians report considerable interest in, but limited use of, telehealth services. J Am Board Fam Med 2017;30:320-30.

44 Ly BA, Bourgeault IL, Labonté R, et al. Physicians' perceptions on the impact of telemedicine on recruitment and retention in underserved areas: a descriptive study in Senegal. Hum Resour Health 2017;15:67.

45 Zayyad MA, Toycan M. Factors affecting sustainable adoption of e-health technology in developing countries: an exploratory survey of Nigerian hospitals from the perspective of healthcare professionals. PeerJ 2018;6:e4436.

46 Meng Q, Mills A, Wang L, et al. What can we learn from China's health system reform? BMJ 2019;365:I2349. 
47 Shaw J, Agarwal P, Desveaux L, et al. Beyond "implementation": digital health innovation and service design. NPJ Digit Med 2018;1:48.
48 Han Y, Lie RK, Guo R. The Internet Hospital as a telehealth model in China: systematic search and content analysis. J Med Internet Res 2020;22:e17995.

49 Rahimi K. Digital health and the elusive quest for cost savings. Lancet Digit Health 2019;1:e108-9. 